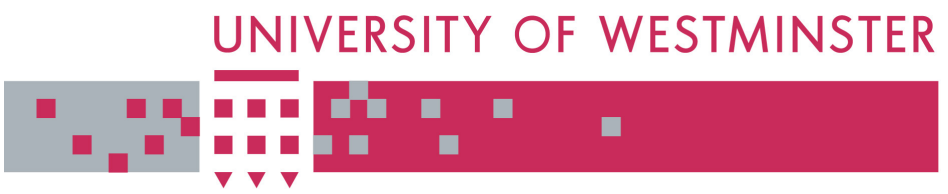

WestminsterResearch

http://www.wmin.ac.uk/westminsterresearch

\title{
Linearization of power amplifiers by baseband digital predistortion for OFDM transmitters
}

\author{
Dmytro Bondar ${ }^{1}$ \\ Djuradj Budimir ${ }^{1}$ \\ Boris Shelkovnikov ${ }^{2}$ \\ ${ }^{1}$ School of Informatics, University of Westminster \\ ${ }^{2}$ National Technical University of Ukraine
}

Copyright (C) [2008] IEEE. Reprinted from 18th International Crimean Conference "Microwave \& Telecommunication Technology" (CriMiCo'2008). 8-12 September, Sevastopol, Crimea, Ukraine. IEEE, Los Alamitos, USA, pp. 270-271. ISBN 9789663351698.

This material is posted here with permission of the IEEE. Such permission of the IEEE does not in any way imply IEEE endorsement of any of the University of Westminster's products or services. Personal use of this material is permitted. However, permission to reprint/republish this material for advertising or promotional purposes or for creating new collective works for resale or redistribution to servers or lists, or to reuse any copyrighted component of this work in other works must be obtained from the IEEE. By choosing to view this document, you agree to all provisions of the copyright laws protecting it.

The WestminsterResearch online digital archive at the University of Westminster aims to make the research output of the University available to a wider audience. Copyright and Moral Rights remain with the authors and/or copyright owners.

Users are permitted to download and/or print one copy for non-commercial private study or research. Further distribution and any use of material from within this archive for profit-making enterprises or for commercial gain is strictly forbidden.

Whilst further distribution of specific materials from within this archive is forbidden, you may freely distribute the URL of the University of Westminster Eprints (http://www.wmin.ac.uk/westminsterresearch).

In case of abuse or copyright appearing without permission e-mail wattsn@wmin.ac.uk. 


\title{
LINEARIZATION OF POWER AMPLIFIERS BY BASEBAND DIGITAL PREDISTORTION FOR OFDM TRANSMITTERS
}

\author{
Dmytro Bondar ${ }^{1}$, Djuradj Budimir ${ }^{1}$ and Boris Shelkovnikov ${ }^{2}$ \\ 1-Wireless Communication Research Group, University of Westminster \\ 115 New Cavendish Street, London, UK, W1W 6UW \\ 2-National Technical University of Ukraine ("KPI") \\ 37 Pobedy Avenue, Kiev, Ukraine, 03056 \\ E-mail:bshelk@gmail.com /D.Bondar1@westminster.ac.uk
}

\begin{abstract}
For the signals with high peak-to-average ratio (PAR), such as WiMax OFDM, power amplifiers need to operate in a compression mode. It results in a non-linear distortion of the output signal. To compensate for this distortion, linearizers are used. However, they decrease efficiency of amplifiers. This paper proposes to use a digital predistortion of baseband signals, which is characterized by a small impact on efficiency and a good linearizing performance, for linearization of OFDM transmitters. The paper describes design of a baseband predistorter and verifies its performances by WiMax OFDM simulations in ADS. Proposed predistorter brings significant improvements in AM/AM characteristic, eliminates spectrum re-growth, decreases adjacent channel power ratio (ACPR) and error vector magnitude (EVM).
\end{abstract}

\section{Introduction}

Modern standards of wireless communication systems, such as UMTS and WiMax, are characterized by high peak-to-average ratio (PAR). High PAR and high efficiency demands lead to severe requirements for power amplifiers (PA). To satisfy these requirements, PAs need to operate in a compression mode. Operation in a nonlinear mode degrades performances of the output signal. Therefore, linearizing techniques should be introduced to minimize the output distortion.

Many techniques of linearization have been recently proposed [1]-[4]. The most commonly used linearizers are produced either in RF feedback [2], RF feed-forward [4], $\mathrm{RF}$ analog predistortion [2] or digital predistortion (DPD) [1], [3].

The most rapidly developing linearization technique is digital predistortion (DPD). This is a popular and reliable technique that allows minimising output distortion and spectral re-growth, as well as maximizing power efficiency by digitally processing the input signal to produce a highly linear output [1], [3]. The most developed DPD methods are look-up-table (LUT) and polynomial. Both of them need a feedback loop, adjuster and complex LUT or polynomial block. That makes the whole DPD circuit complicated and big size.

In this paper, a baseband signal injection digital predistortion method is proposed. Its main advantages are small size, high efficiency and low cost due to the absence of feedback loops. Moreover, described linearizer is simple for realisation and provides good linerizing performances, which has been proved by the WiMax OFDM simulation results.

\section{Description of the Baseband DPD}

Theoretical analysis of a signal distortion after passing $P A$ in saturation has been presented in our previous paper [1]. Non-linearity of the amplifier is expressed in a polynomial form (1). The distorted signal includes new spectral components at fundamental frequency and new terms at double, triple, etc frequencies.

$$
V_{\text {OUT }}(t)=g_{1} \cdot V_{\mathrm{IN}}(t)+g_{2} \cdot V_{\mathrm{IN}}^{2}(t)+g_{3} \cdot V_{\mathrm{IN}}^{3}(t)+\ldots
$$

Where $V_{\mathrm{IN}}$ is the input voltage of the PA and $g_{1}, g_{2}$, $g_{3}$ are coefficients of the nonlinear terms.

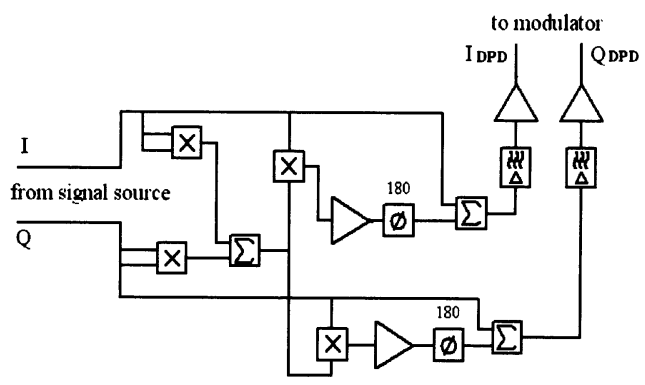

Figure 1. Block diagram of the proposed linearizer

The main idea of the proposed technique is to find the resulting distorted baseband signals $I$ and $Q$, to extract distortion components and to inject these components into the original baseband signal with the same magnitude and opposite phase to compensate for the distortion generated by a PA non-linearity. In real system, tuning of the coefficients near injected distortion components must be provided in order to achieve the best linearization.

The predistorted I and $Q$ signal for the $3^{\text {rd }}$-order polynomial model look like [1]

$$
\begin{aligned}
& I_{\mathrm{DPD}}=\left(1-\frac{3 V^{2} g_{3}}{4 g_{1}}\left(I^{2}+Q^{2}\right)\right) I \\
& Q_{\mathrm{DPD}}=\left(1-\frac{3 V^{2} g_{3}}{4 g_{1}}\left(I^{2}+Q^{2}\right)\right) Q
\end{aligned}
$$

Where $I$ and $Q$ - are initial baseband signals.

Therefore, predistorted input signal can be written as:

$$
V_{\mathrm{IN}}^{\mathrm{DPD}}(t)=V\left(I_{\mathrm{DPD}} \cos \omega t-Q_{\mathrm{DPD}} \sin \omega t\right)
$$

After passing though PA non-linearity (1), this signal will produce distortion components, which eliminate each other at the fundamental frequency. In [1] it was shown that only the odd components of the non-linear model (1) bring distortion to the fundamental signal. This explains appearance in (2)-(3) only coefficients $g_{1}$ and $g_{3}$, but not $g_{2}$.

A block diagram of the proposed linearizer is shown on Fig. 1. It realises mathematical operations with I and $Q$ signals described by (2)-(3). The improvements in linear performances achieved by using described baseband DPD linearizer (Fig. 1) for a WiMax OFDM signal are presented in the following section.

\section{WiMax OFDM Simulation Results}

In order to demonstrate linearizing performances of the proposed baseband predistorter (Fig. 1), Advanced Design System (ADS) simulations were carried out with a 256-OFDM 64QAM WiMax signal. 
Initial I and Q signals for 64-QAM modulation with $2^{3}=8$ possible levels are generated in the signal source. These signals are then predistorted according to (2)-(3) in the digital predistorter. Subsequently, they are passed through low-pass filters and multiplied by $V$ in order to achieve a proper level for the modulator input (Fig. 1).

Adjusted $I$ and $Q$ signals are modulated for 256-OFDM 64-QAM WiMax signal in the modulator with $3.5 \mathrm{GHz}$ RF carrier frequency, $7 \mathrm{MHz}$ bandwidth, and frequency spacing of $31.25 \mathrm{kHz}$.

Achieved RF signal further goes to a WiMax PA, which operates in a compression mode. The PA performances were investigated for two cases: passing through WiMax signal with and without digital predistortion.

Changing input power from -40 to $25 \mathrm{dBm}$, the $A M / A M$ characteristics were obtained (Fig. 2). The dotted line represents output power verses input power for the case without DPD and solid line - for the one with DPD. As can be observed from the graph, amplifier goes into compression mode at $0 \mathrm{dBm}$ input without predistortion; while after DPD, compression begins to appear at input of more than $10 \mathrm{dBm}$. Moreover, after implementing DPD this part is not as curved as before.

Investigations of the impact of proposed DPD on ACPR and EVM were carried out. In order to investigate ACPR, the offset of $8 \mathrm{MHz}$ for both low and up channels has been chosen. The output power was considered for the range $-5 . .30 \mathrm{dBm}$. Corresponding graphs are shown on Figure 3. As can be seen from the graphs, predistortion brings improvement of $8 . .10 \mathrm{~dB}$ in ACPR.

Figure 4 shows simulation results for EVM for the considered signal with and without predistortion. According to the WiMax standard, it should not be more than $2.7 \%$. Fig. 4 demonstrates that the proposed method brings Improvement into EVM characteristic.

Furthermore linearizer was investigated for spectrum re-growth. Figure 5 shows output signal spectrums with and without predistortion for $0-\mathrm{dBm}$ input power. $21 \mathrm{~dB}$ improvement was achieved by using the proposed method (Fig. 5).

\section{Conclusion}

A baseband injection technique for linearization of power amplifiers has been presented. Performances of the digital predistortion circuit have been investigated. The 256-OFDM 64-QAM WiMax signal with $3 \mathrm{GHz}$ carrier, 7 $\mathrm{MHz}$ bandwidth and $31.25 \mathrm{kHz}$ spacing between channels was used. Spectrum re-growth, transfer function, ACPR and EVM improvements were achieved. Spectrum regrowth improvement of $21 \mathrm{~dB}$ was obtained for $0-\mathrm{dBm}$ power input. Proposed linearizer circuit is small-size, low cost, and easy to implement.

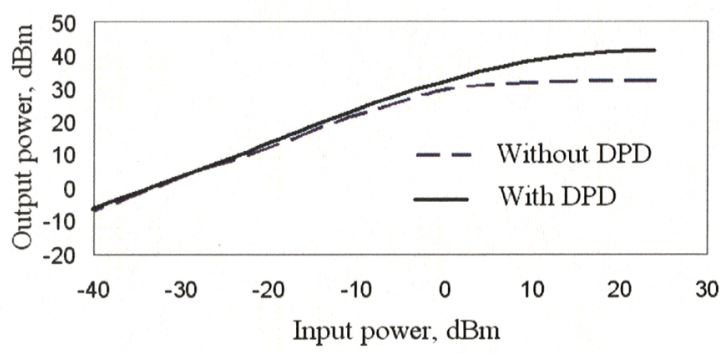

Figure 2. Transfer characteristic of the $P A$ with and without $D P D$

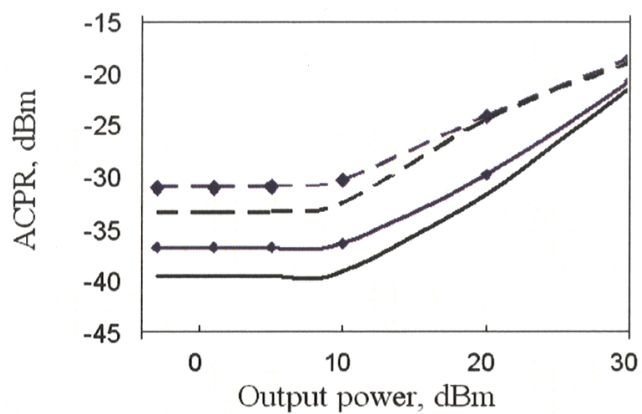

$\rightarrow-\mathrm{ACPR} U$ without DPD $\rightarrow$ ACPR U with DPD

- - ACPRL without DPD - ACPRL with DPD

Figure 3. ACPR with and witpout predistortion for $8 \mathrm{MHz}$ up and low offsets

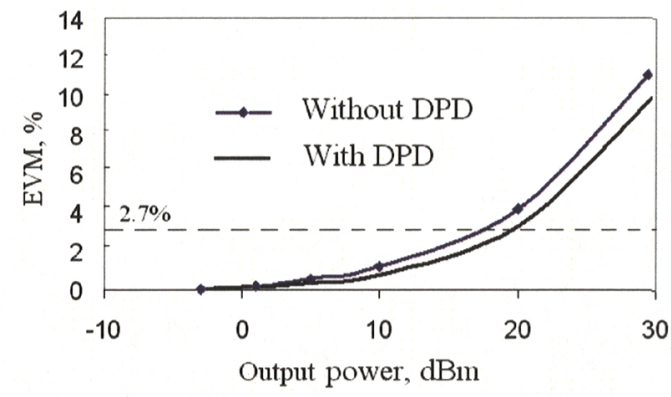

Figure 4. EVM with and without predistortion

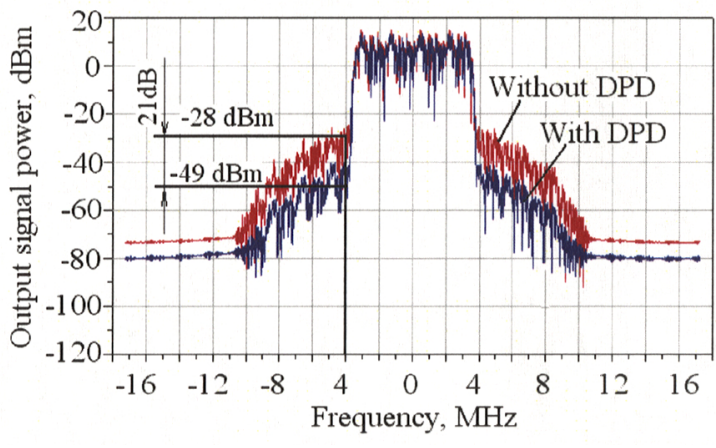

Figure 5. PA output spectrum with 256-OFDM 64-QAM WiMax signal and input power $0 \mathrm{dBm}$

\section{References}

[1] D. Bondar, and D. Budimir, "WiMax power amplifier linearisation through injection of base-band component", $11 \mathrm{~h}$ International Symposium on Microwave and Optical Technology (ISMOT-2007), Roma, Italy, 17 - 21 December 2007.

[2] Hu Y., Mollier J. C. and Obregon J., "A new method of third order IMD reduction in nonlinear microwave systems", IEEE Trans. Microwave Theory and Tech. MTT-34, pp. 245 - 250 February 1986.

[3] K. K. M. Cheng, and C. S. Leung, "A novel generalized lowfrequency signal injection method for multistage amplifier linearization", IEEE Trans. Microwave Theory and Tech. Vol. 51, No. 2, pp. 553-559, February 2003.

[4] Ogawa T., Iwasaki T., Maruyama H., Horiguchi K., Nakayama M., Ikeda $Y$., and Kurebayashi $H$., "High efficiency feed-forward amplifier using RF predistortion linearizer and the modified Doherty Amplifier", IEEE MIT-S Digest, pp. 537$540,2004$. 